\title{
The Microwave Thermal Thruster Concept
}

\author{
Kevin L.G. Parkin, Leo D. DiDomenico, Fred E.C. Culick \\ Division of Engineering and Applied Science, California Institute of Technology, \\ 1200 East California Boulevard, Pasadena, CA 91125, USA
}

\begin{abstract}
The microwave thermal thruster heats propellant via a heat-exchanger then expands it through a rocket nozzle to produce thrust. The heat-exchanger is simply a microwave-absorbent structure through which propellant flows in small channels. Nuclear thermal thrusters are based on an analogous principle, using neutrons rather than microwaves, and have experimentally demonstrated specific impulses exceeding 850 seconds. A microwave equivalent will likely have a similar specific impulse, since both nuclear and microwave thermal thrusters are ultimately constrained by material thermal limits, rather than the energy-density limits of chemical propellants. We present the microwave thermal thruster concept by characterizing a novel variation for beamedenergy launch. In reducing the thruster concept to practice, the enabling physical process is microwave absorption by refractory materials, and we examine semiconductor and susceptor-based approaches to achieving this absorption within the heat-exchanger structure.
\end{abstract}

\section{INTRODUCTION}

A microwave thermal thruster is the enabling component of the beamed-microwave launch concept examined in an accompanying paper [1]. This concept calls for a microwave thermal thruster residing on the flat underside of a lifting body aeroshell. It uses a hydrogen propellant, delivering $54 \mathrm{kN}$ of thrust at a vacuum specific impulse $\left(\mathrm{I}_{\mathrm{sp}}\right)$ of 1030 seconds. It must maintain this performance as the microwave beam incidence varies from normal to $\pm 45^{\circ}$, and the thruster should weigh less than $90 \mathrm{~kg}$, or roughly half of the vehicle structural mass budget.

This thruster, shown in figure 1, is essentially a heat-exchanger in which a high pressure hydrogen propellant flows through 1000 square channels, each $2.4 \mathrm{~mm}$ wide. The hydrogen channel flow is accelerated toward sonic velocity as a Rayleigh flow, in which energy addition by convective heat transfer with the channel walls is the source of increasing kinetic and thermal energy. For the design presented here, the hydrogen exit temperature is $2800 \mathrm{~K}$, corresponding to a vacuum $\mathrm{I}_{\mathrm{sp}}$ of 1030 seconds.

Launch vehicle propulsion by a hydrogen heat exchanger is not new. From the 1950 s to the 1970s a series of over 30 nuclear thermal thruster tests, conducted as part of the KIWI and NERVA programs, experimentally demonstrated that the hydrogen heat-exchanger approach can produce an $\mathrm{I}_{\mathrm{sp}}$ of 850 seconds [9]. These tests also demonstrated that the heat exchanger can operate at power levels exceeding $1 \mathrm{GW}$ (for high thrust), and for durations of over an hour. Performance is ultimately constrained by the temperature limits of refractory materials with suitable uranium compatibility and neutronic 


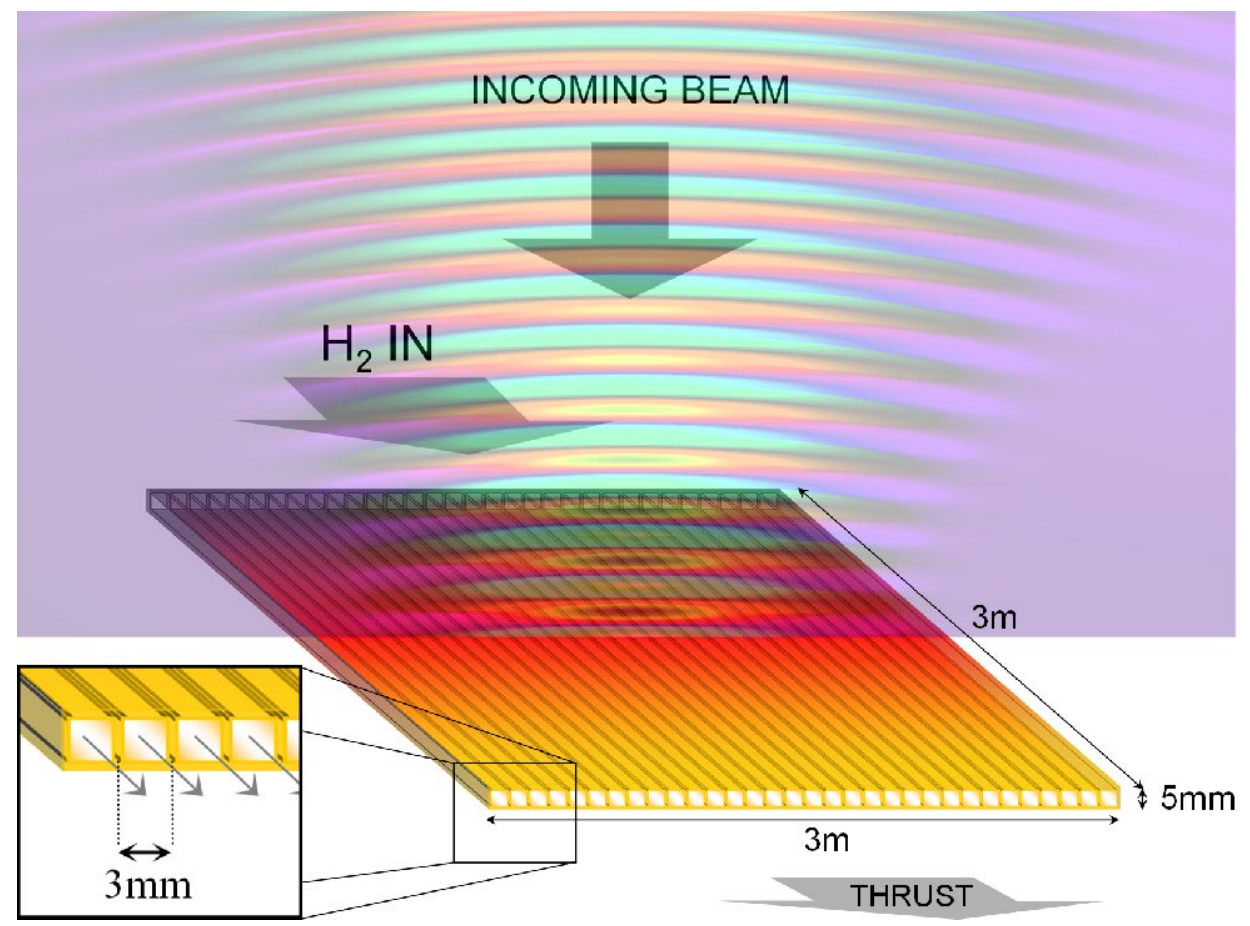

FIGURE 1. The $275 \mathrm{MW}, 55 \mathrm{kN}$ microwave thermal thruster.

properties. Microwave thermal thrusters are temperature limited in a similar way, but the choice of refractory materials is constrained by microwave optical properties. The thruster geometry is different too; unlike nuclear rockets, which contain a neutron gas in a cylindrical heat exchange geometry using neutron reflective walls, the microwave rocket intersects a transatmospheric microwave beam in the most efficient way possible, which is upon a flat absorbing surface.

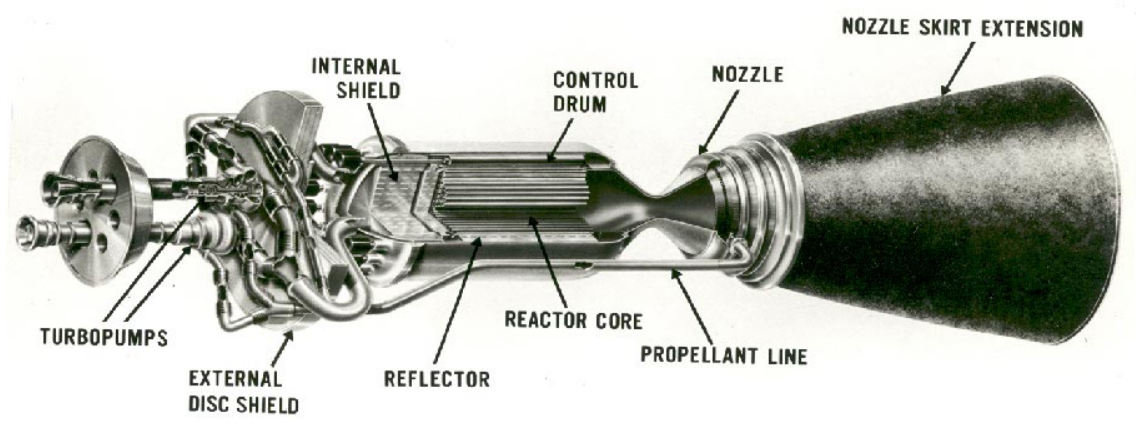

FIGURE 2. A 1970 schematic of the NERVA nuclear thermal rocket engine (NASA Image No. NPO-70-15803). 
Microwave thermal thrusters inherently operate at peak microwave energy absorption. Unlike the breakdown of a high power laser mirror or the reactor meltdown of figure $8 \mathrm{c}$, many types of malfunction in the microwave thermal thruster should only serve to decrease the microwave absorption, and slow or stop the progression of a fault.

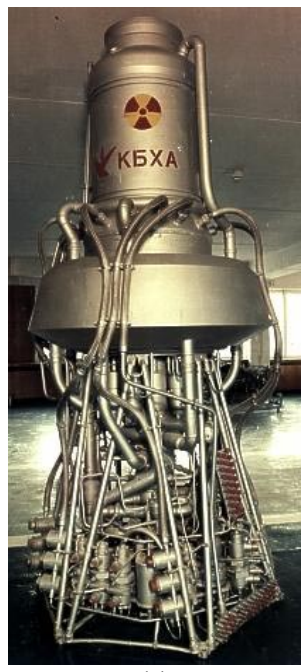

(a)

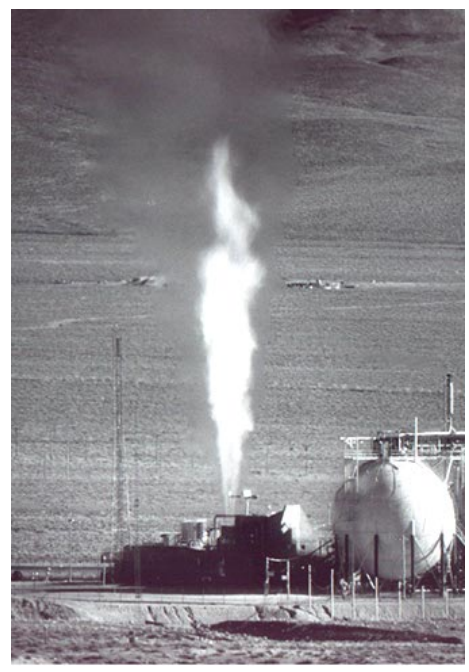

(b)

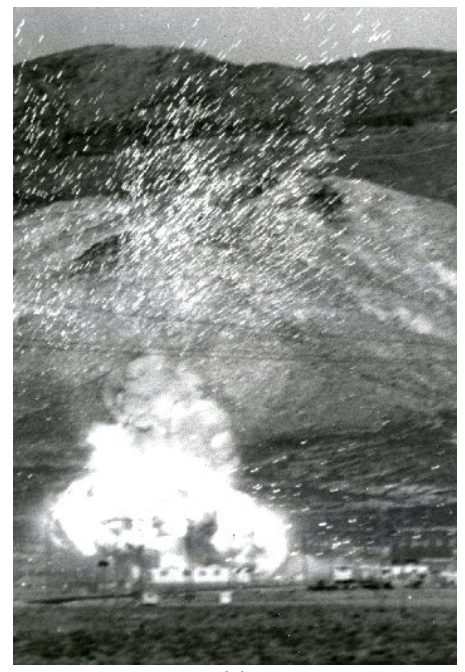

(c)

FIGURE 3. (a) The RD-0410 Nuclear Thermal Engine (C Dietrich Haeseler). (b) NERVA nuclear thermal rocket test. (National Air and Space Museum, Smithsonian Institution (SI 75-13750)). In December 1967, an experimental version of NERVA completed a 60-minute endurance test at $2270 \mathrm{~K}$ and $1100 \mathrm{MW}$. (c) Launch accident simulation using a modified Kiwi Nuclear Rocket in January 1965. A sudden increase in power output was imposed, causing the reactor to explode. (NASA Image No. 65-H-49).

\section{PERFORMANCE}

\section{Gasdynamics}

A simple estimate of thruster performance can be made by assuming that enthalpy is conserved from the constant area channel exit, shown in the lower left corner of figure 1, through to the ambient atmospheric pressure. The resulting conservation equation can be manipulated using well-known perfect gas relations to give

$$
I_{s p}=\frac{1}{g} \sqrt{2 c_{p}\left(T_{t}^{*}\right) T_{t}^{*}\left(1-\frac{p_{a}}{p_{t}^{*}}\right)^{\gamma-1 / \gamma}}
$$

where all quantities denoted by * are measured at the heat exchanger channel exit, immediately prior to nozzle expansion. Quantities with subscript $t$ are total quantities, 
and those without this subscript are static where applicable. $T_{t}^{*}$ is the total temperature at the channel exit and is equal to peak wall temperature within a nondimensional constant close to unity. The specific heat capacity $c_{p}$ is calculated using a NIST approximation [2], and $\gamma$ is assumed constant throughout the expansion. $\mathrm{p}_{\mathrm{a}}$ is the ambient atmospheric pressure.

Choosing a peak wall temperature of $2800 \mathrm{~K}$ and total pressure of $50 \mathrm{~atm}$ at the channel exit, equation (1) can be combined with a standard atmospheric model to give the variation of $I_{s p}$ with altitude shown in figure 4 . This is the $I_{s p}$ profile used in the ascent trajectory analysis of [1].

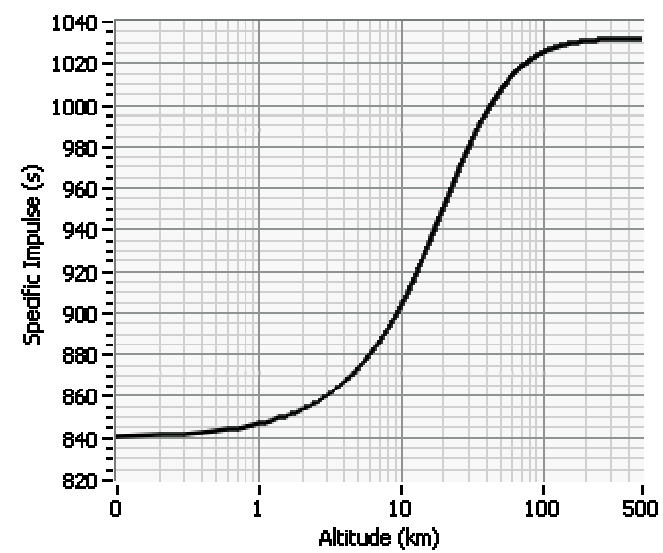

FIGURE 4. Variation of specific impulse with altitude for an optimally expanded hydrogen thruster with $2800 \mathrm{~K}$ peak wall temperature.

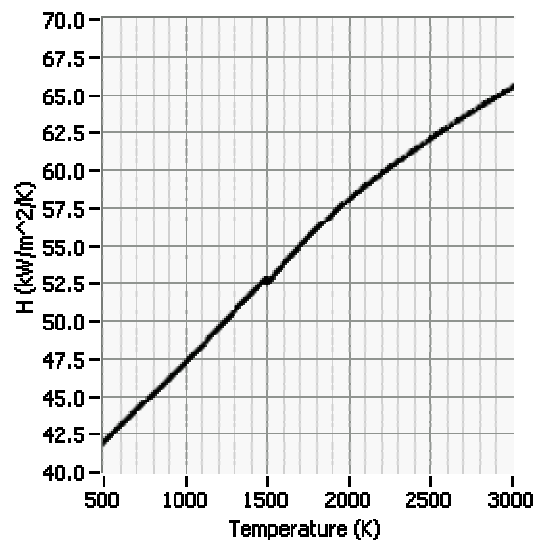

FIGURE 5. Convective heat transfer coefficient for hydrogen in a square channel $2.4 \mathrm{~mm}$ wide.

Convective heat transfer into an $\mathrm{H}_{2}$ propellant along the channel and beam spot size together drive the detailed engine design. The power transferred into the propellant is the product of the convective heat transfer coefficient $\mathrm{H}$ and the temperature difference between the bulk flow and channel wall at any given point along the channel. The channel flow is fully turbulent with a Reynolds number above 10000, so that the convective heat transfer is described in nondimensional form by [3]

$$
\mathrm{Nu}=0.023 \operatorname{Re}^{0.8} \operatorname{Pr}^{1 / 3}
$$

where the Nusselt, Reynolds, and Prandtl numbers are given by

$$
\mathrm{Nu}=\frac{H D}{K}, \quad \operatorname{Re}=\frac{\rho \bar{u} D}{\mu}=\left(\frac{\dot{m}}{A}\right)\left(\frac{D}{\mu}\right), \quad \operatorname{Pr}=\frac{\mu c_{p}}{K}
$$

For $\mathrm{H}_{2}$ in the range $300-3000 \mathrm{~K}$ we can assume $\mathrm{Pr} \sim 0.73$. Equations $(2,3)$ can be rearranged to find the heat transfer coefficient in terms of the channel geometry and hydrogen properties, giving 


$$
\mathrm{H}_{\mathrm{H}_{2}}=0.021 \frac{K}{D}\left(\frac{\dot{m}}{A} \frac{D}{\mu}\right)^{0.8}
$$

For a channel of square cross-section, rather than circular, the heat transfer coefficient given by (4) is multiplied by 0.76 [3] and is shown for a square channel in figure 5. $\mu(\mathrm{T})$ is calculated using Sutherland's law and relevant constants for $\mathrm{H}_{2}$ [4]. $\mathrm{C}_{\mathrm{p}}(\mathrm{T})$ is calculated as before, and $\mathrm{K}(\mathrm{T})$ is deduced from these values and the Prandtl number, equal to 0.73 for $\mathrm{H}_{2}$. The thruster provides $275 \mathrm{MW}$ of jet power through 1000 identical channels, hence $275 \mathrm{~kW}$ per channel. Assuming uniform power density along the channel, the necessary power can be absorbed by the propellant in each channel by maintaining the walls at roughly $230 \mathrm{~K}$ hotter than the bulk flow at the thruster entrance $\left(\mathrm{T}_{\mathrm{H} 2}=500 \mathrm{~K}\right)$ and $140 \mathrm{~K}$ at the thruster exit $\left(\mathrm{T}_{\mathrm{H} 2}=2800 \mathrm{~K}\right)$. Note that the propellant pressure modifies the melting point of the channel walls.

Mass flow rate per unit channel area $(\dot{m} / A)$ is a function of wall temperature and exit pressure, deduced from continuity at the nozzle to be

$$
\frac{\dot{\mathrm{m}}}{\mathrm{A}^{*}}=p^{*} M^{*} \sqrt{\frac{\gamma}{R T^{*}}}
$$

where $\mathrm{p}^{*}$ and $\mathrm{T}^{*}$ are static temperature and pressure. $\mathrm{M}^{*}$ is the channel exit Mach number and is used to deduce the total temperature and pressure from the static values. Choosing $M^{*}=1, T_{t}^{*}=2800 \mathrm{~K}$, and $p_{t}^{*}=50 \mathrm{~atm},(\dot{m} / \mathrm{A})$ is found to be approximately $1180 \mathrm{~kg} / \mathrm{m}^{2} / \mathrm{s}$. This value is sensitive to the precise thermodynamics of hydrogen, so the variation of $\gamma$ and $c_{p}$ with temperature should be taken into account.

Worst-case radiative losses from the thruster are estimated by assuming that the entire thruster area is a black body radiating at peak wall temperature. With a surface area of $9 \mathrm{~m}^{2}$ at a temperature of $2800 \mathrm{~K}$, the thruster of figure 1 would lose $31.4 \mathrm{MW}$, or approximately one eighth of the jet power $(275 \mathrm{MW})$, by radiation from the outer surface.

\section{Materials}

The thrust to weight ratio of the engine is important because the thruster should weigh no more than $90 \mathrm{~kg}$; about half of the structural mass of the vehicle. Materials must be used efficiently within the thruster structure to achieve this goal. Channel pressure and mass flow rate drive the structural design of the thruster channels. A peak thruster mass flow rate of $5 \mathrm{~kg} / \mathrm{s}$ can be estimated from peak thrust and vacuum $\mathrm{I}_{\mathrm{sp}}$. Dividing this by the $1180 \mathrm{~kg} / \mathrm{m}^{2} / \mathrm{s}$ found from (6) gives us a total required channel exit area of $0.0044 \mathrm{~m}^{2}$, which can be made up of area contributions from many small channels.

As an example, we choose a thruster structure consisting of $10002.37 \mathrm{~mm} \times 2.37 \mathrm{~mm}$ channels surrounded by a $1 \mathrm{~mm}$ thick layer on all sides, as shown in figure 1 . The material volume fraction of this $3 \mathrm{~m}$ wide, $5 \mathrm{~mm}$ high, thruster is $37 \%$. Assuming an average material density of $3.2 \mathrm{~g} / \mathrm{cm}^{3}$, this gives a thruster mass of $90.5 \mathrm{~kg}$, very close to the $90 \mathrm{~kg}$ goal, but leaving little room for structural over-engineering. This example 
demonstrates that for the microsatellite launcher examined in [1], the channels must be square, rather than round, so that the weight of unnecessary thruster material does not reduce the payload mass. Maintaining 50 atmospheres within these thin-walled channels requires high material strength at high temperature, but strength is not the only criteria for material selection. Table 1 lists other properties that must be taken into account also.

Some of the strongest, purest, forms of the materials shown in table 1 are formed into custom structures by chemical vapor deposition (CVD) [5], and it may be possible to vapor deposit such a thin thruster directly onto the aeroshell. CVD materials also tend to possess the fullest anisotropy of a material's underlying crystal structure, and hexagonal boron nitride is a case in point. Though we do not treat anisotropy here, it can be exploited to spread heat laterally but not vertically, for example.

TABLE 1. Data for some materials of interest [5].

\begin{tabular}{|c|c|c|c|}
\hline Property & $\beta-\mathrm{SiC}$ & HfC & h-BN \\
\hline Melting point & $\begin{array}{c}2818 \mathrm{~K}(1 \mathrm{~atm}) \\
3103 \mathrm{~K}(35 \mathrm{~atm})\end{array}$ & $4200 \mathrm{~K}$ (1 atm) & $3273 \mathrm{~K}(1 \mathrm{~atm})$ \\
\hline Density & $3.214 \mathrm{~g} / \mathrm{cm}^{3}$ & $12.67 \mathrm{~g} / \mathrm{cm}^{3}$ & $1.9 \mathrm{~g} / \mathrm{cm}^{3}$ \\
\hline Oxidation resistance & $\begin{array}{c}\text { Forms protective } \mathrm{SiO} 2 \\
\text { layer at } 1500 \mathrm{~K} \text {, layer } \\
\text { is stable to } 1900 \mathrm{~K} \text {. }\end{array}$ & $\begin{array}{c}\text { Oxidation begins in air } \\
\text { above } 770 \mathrm{~K} .\end{array}$ & $\begin{array}{c}\text { Oxidation begins } \\
\text { above } 1000 \mathrm{~K} \text { at a rate } \\
\text { increasing to } 10 \\
\mathrm{mg} / \mathrm{cm}^{2} / \mathrm{min} \text { at } 2000 \mathrm{~K} \text {. }\end{array}$ \\
\hline Hydrogen resistance & $\begin{array}{l}\mathrm{H}_{2} \text { reported to slowly } \\
\text { etch } \mathrm{SiC} \text { at } \sim \mathrm{nm} / \mathrm{s}\end{array}$ & $\begin{array}{l}\text { Compatible with } \mathrm{H}_{2} \text { up } \\
\text { to melting point [9] }\end{array}$ & $\begin{array}{c}\text { Compatible with } \mathrm{H}_{2} \text { up } \\
\text { to } 1650 \mathrm{~K}\end{array}$ \\
\hline Thermal conductivity & $\begin{array}{c}25.5 \mathrm{~W} / \mathrm{m} / \mathrm{K}(293 \mathrm{~K}) \\
11 \mathrm{~W} / \mathrm{m} / \mathrm{K}(1800 \mathrm{~K})\end{array}$ & $20 \mathrm{~W} / \mathrm{m} / \mathrm{K}(293 \mathrm{~K})$ & $28-33 \mathrm{~W} / \mathrm{m} / \mathrm{K}$ \\
\hline Dielectric constant & $9.72(300 \mathrm{~K})$ & & $\begin{array}{l}4.58(\mathrm{ab}) \\
4.15(\mathrm{c})\end{array}$ \\
\hline Resistivity & $\begin{array}{l}10^{-2} \text { to } 10^{6} \Omega . \mathrm{cm}, \\
\text { depending on dopant } \\
(\mathrm{B}, \mathrm{N}, \mathrm{Al})\end{array}$ & $37-45 \mu \Omega . c m(293 \mathrm{~K})$ & $>10^{14} \Omega . \mathrm{cm}(300 \mathrm{~K})$ \\
\hline Notes & $\begin{array}{l}\text { Can be vapor } \\
\text { deposited up to } 1 " \\
\text { thick }\end{array}$ & & $\begin{array}{l}\text { Suitable forms are } \\
\text { hexagonal hot-pressed } \\
\text { and vapor deposited. } \\
\text { CVD form highly } \\
\text { anisotropic. }\end{array}$ \\
\hline
\end{tabular}

As seen in table 1 , the density of $3.2 \mathrm{~g} / \mathrm{cm}^{3}$ used in thruster mass estimate above is the density of silicon carbide, and much greater than the density of boron nitride. The materials in table 1 are each candidate materials for a microwave thermal thruster, and we next show how they can be arranged into an efficient microwave absorbing structure.

\section{Electromagnetics}

\section{Stratified Layer Model}

The fraction of incident microwave energy absorbed or reflected by a thruster can be analytically estimated using a stratified layer model [6], representing electromagnetic propagation within an idealized layered-structure thruster. In addition to demonstrating the optical performance of a thruster design, this model can be used to predict the layer 
thicknesses needed for optimal microwave absorption at the conceptual design stage. Equations (6) are the energy reflection, transmission, and absorption coefficients, which are calculated from the electric field reflection and transmission coefficients given by (7). The angle of incidence and wave polarization enters through (8). The transverse direction is orthogonal to the plane of incidence; hence the electric field component of a transverse electric (TE) wave would oscillate out of the plane of the paper in figures 6 and 10. Material properties also enter through (8), and are assembled into a 'characteristic matrix' for each layer of material, numbered $\mathrm{l}=1$ to $\mathrm{N}-1$, in (9), where $\mathrm{l}=0$ corresponds to the incident medium and $\mathrm{l}=\mathrm{N}$ corresponds to the transmitted medium, both of which are usually free space. Multiplying the characteristic matrix of each layer by the next, an overall characteristic matrix is formed, from whose elements the complex reflectivity and transmissivity are calculated in (7).

$$
\begin{gathered}
R=|r|^{2}, \quad T=\frac{p_{0}}{p_{N}}|t|^{2}, \quad A=1-R-T \\
r=\frac{\left(M_{11}+p_{N} M_{12}\right) p_{0}-\left(M_{21}+p_{N} M_{22}\right)}{\left(M_{11}+p_{N} M_{12}\right) p_{0}+\left(M_{21}+p_{N} M_{22}\right)}, t=\frac{2 p_{0}}{\left(M_{11}+p_{N} M_{12}\right) p_{0}+\left(M_{21}+p_{N} M_{22}\right)} \\
p=\begin{array}{c}
\left.\hat{n} n_{0} \cos \theta\right\} T E \\
\left.\left(1 /\left(\hat{n} n_{0}\right)\right) \cos \theta\right\} T M, \quad \beta=2 \pi \frac{\hat{n} h}{\lambda_{0}} \cos \theta
\end{array} \\
M=\prod_{l=1}^{N-1} m_{l}, \quad m_{l}=\left[\begin{array}{cc}
\cos \beta_{l} & -\left(i / p_{l}\right) \sin \beta_{l} \\
-i p_{l} \sin \beta_{l} & \cos \beta_{l}
\end{array}\right] \\
\hat{n}=\sqrt{\mu\left(\varepsilon_{D C}+i \frac{18 \times 10^{9} \hat{\sigma}}{f}\right)}, \quad \hat{\sigma}=\frac{\sigma_{D C}}{1-i \frac{f \varepsilon_{D C}}{2 \sigma_{D C}}}
\end{gathered}
$$

Finally, the complex refractive index $\hat{n}$ is related to widely available DC material properties via the Drude model in (10). The dielectric constant is assumed to remain at its DC value throughout the microwave frequency range. $\mathrm{n}_{0}$ is the absolute refractive index of free space, $\mathrm{f}$ is microwave frequency in $\mathrm{Hz}$, and $\sigma$ is conductivity in $\mathrm{S} / \mathrm{m}$.

\section{Silicon Carbide Thruster}

Silicon carbide $(\mathrm{SiC})$ is a wide band-gap semiconductor used as a microwave absorbent material in microwave furnaces. It is also a highly oxidation resistant refractory material

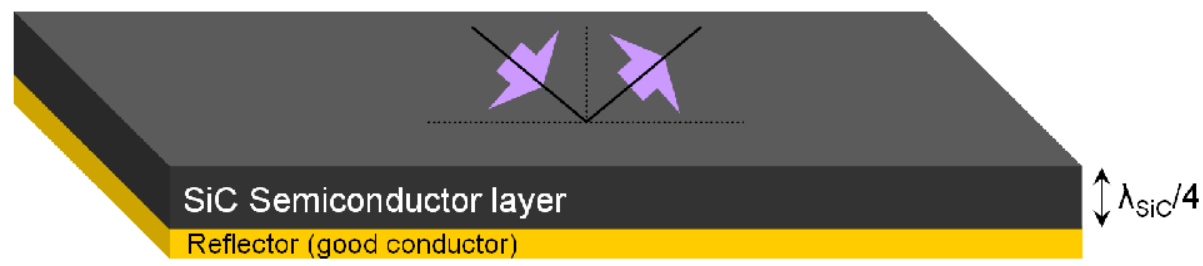

FIGURE 6. An idealization of the $\mathrm{SiC}$ absorber layer structure. 
used on the re-entry heat shield of the space shuttle. Its cubic $(\beta)$ form can be doped to tailor resistivity over an 8 order of magnitude range. For $\beta$-SiC, we can exploit this capability at the design stage to 'tune' the material plasma frequency to match the frequency of incoming microwaves, thereby maximizing absorption at this resonance.

The stratified layer model shown in figure 6 consists of a semiconductor layer with reflector underneath to maximize absorption. Reflection from the semiconducting layer is minimized by choosing the thickness to be a quarter wavelength, like an anti-reflection coating. The wavelength within the material is simply the free space wavelength divided by the real part of the refractive index, which varies with resistivity. For $2.45 \mathrm{GHz}$ microwaves, as might be used in a small-scale demonstration, the optimum $\mathrm{SiC}$ thickness is $1.2 \mathrm{~cm}$ at a resistivity of $100 \Omega . \mathrm{cm}$. At this thickness, the channels could be situated within the $\mathrm{SiC}$ layer. At $140 \mathrm{GHz}$, figure 7 (top) shows impressive absorption of over $95 \%$ at a resistivity of $1.5 \Omega . \mathrm{cm}$, corresponding to a layer thickness of 220 microns. This may sound thin, but by comparison the thickness of an $\mathrm{MgF}_{2}$ anti-reflection coating as found on binocular and camera lenses is about $100 \mathrm{~nm} ; 2200$ times thinner!
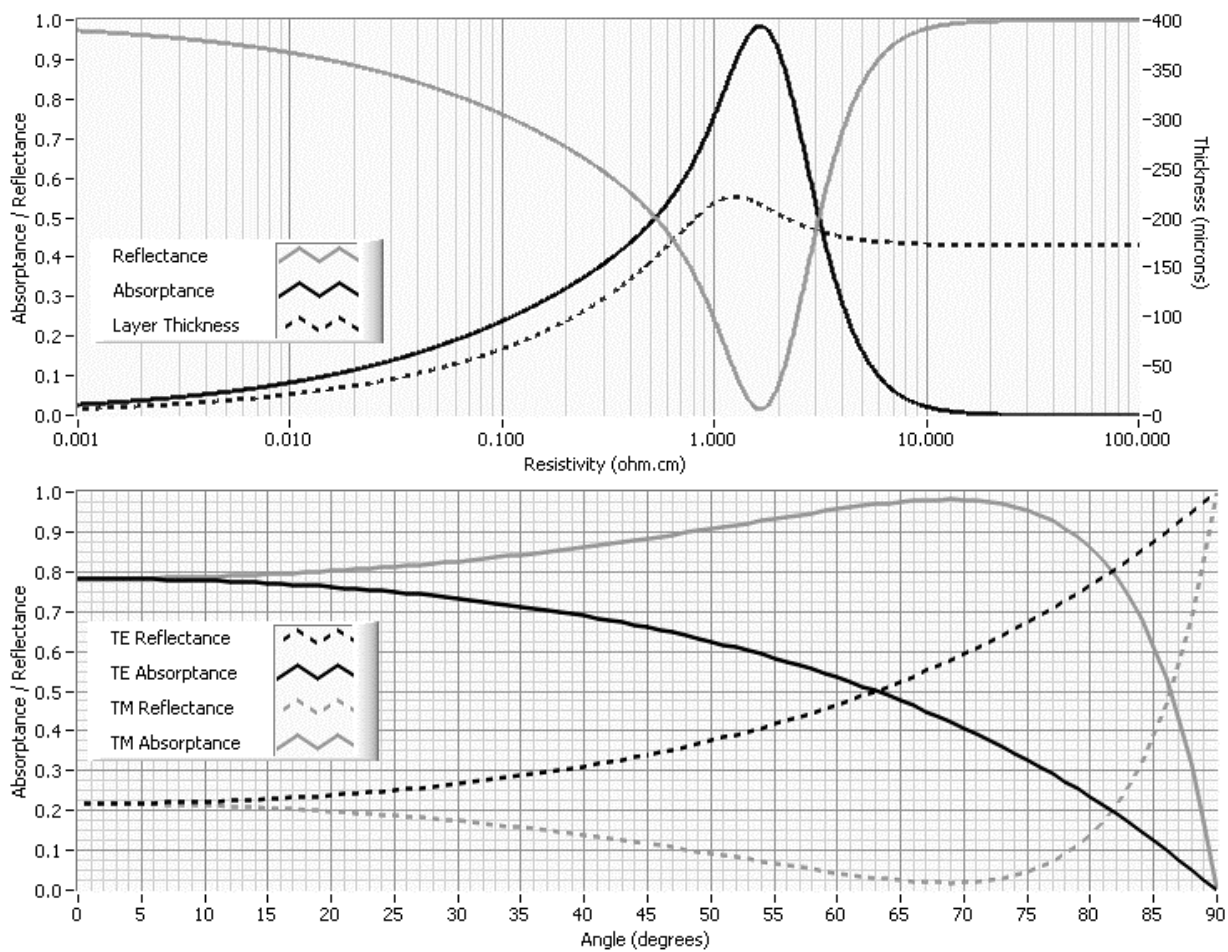

FIGURE 7. (Top) $\mathrm{SiC}$ absorber performance at $140 \mathrm{GHz}$.

(Bottom) $1 \mathrm{~mm}$ thick SiC absorber off-normal response at $140 \mathrm{GHz}, 1.5 \Omega . \mathrm{cm}$ 
Because $\mathrm{SiC}$ is a semiconductor, a $1 \mathrm{~mm}$ layer of $1.5 \Omega$.cm resistivity will absorb $80 \%$ of the incident energy, and the channel walls shown in figure 1 are layers of this thickness. The absorption occurs within the first few hundred microns of the surface, and this is seen in figure 7 for an angle of zero degrees. Remarkably, this figure also shows that the absorption fraction of a TM-polarized wave actually increases with off-normal angle up to a maximum of over $95 \%$ at 70 degrees; more than needed for the launcher ascent trajectory!

If a thinner layer must be used, an $\mathrm{SiC}$ layer 220 microns thick can be deposited onto a microwave transparent material that forms the load-bearing structure. Deposition directly on the inner channel surface provides heat input directly next to the hydrogen flow; deposition on the top (outer) surface of the thruster provides oxidation resistance as well as heating.

A multi-material thruster of this kind needs to avoid thermal expansion mismatches, which could cause delamination of the $\mathrm{SiC}$ layer. A single layer system is preferable because it is simpler. At $140 \mathrm{GHz}$, a single material thruster might be achieved using doped boron nitride, provided that suitable dopants (possibly magnesium) can be found. Depending on the dopant used, the entire material would be permeated with dopant, or just thin layers on the inner channel surfaces, where heating is most efficient. Indeed, the analysis presented here uses only room temperature material properties because high temperature data is not readily available, however at $2000 \mathrm{~K}$ the resistivity of even undoped $\mathrm{BN}$ can drop by ten orders of magnitude [7], bringing it close to the useful semiconducting range.

\section{Hafnium Carbide Thruster}

Hafnium carbide (HfC) is one of the poorest electrical conductors of the ultra-refectory metal alloys, and also the most refractory material known, with a melting point of $4200 \mathrm{~K}$ ( $380 \mathrm{~K}$ above that of diamond). A good conductor efficiently reflects energy, and a good insulator efficiently transmits it. Between these two extremes, a poor conductor absorbs energy by Joule heating. Again, this effect can be optimized by tailoring the thickness of the poorly conducting layer, and such a layer is called a susceptor [8].

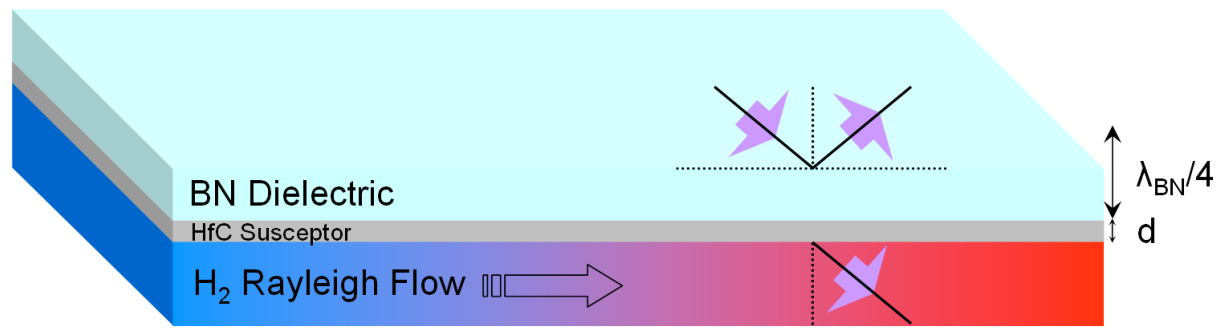

FIGURE 8. An idealization of the HfC thruster layer structure. 
The HfC susceptor is shown in figure 9. A thin susceptor absorbs no more than $50 \%$ of the incident energy; however this efficiency is increased by the boron nitride dielectric layer acting as an anti-reflection coating. The free space wavelength at $140 \mathrm{GHz}$ is 2.14 $\mathrm{mm}$, and so within the $\mathrm{BN}$ the wavelength is $1 \mathrm{~mm}$. By maintaining the thickness at an odd number of quarter wavelengths $(0.25 \mathrm{~mm})$ within reasonable tolerance, the $\mathrm{BN}$ layer can achieve this anti-reflection property in practice.

Even with the poor conductivity of HfC, the optimum susceptor absorption of $80 \%$ at 140 $\mathrm{GHz}$ requires a layer only $6 \mathrm{~nm}$ thick, as seen in figure 10 . Using this $6 \mathrm{~nm}$ thickness, the off-normal incidence profile is shown in figure 11. In this case, the TE-polarized wave is absorbed more efficiently as the source tilts even 65 degrees off-normal. In the ascent trajectory, this means that peak absorption efficiency would correspond to the initial and final stages of horizontal acceleration, above the atmosphere, when one might intuitively expect the least.
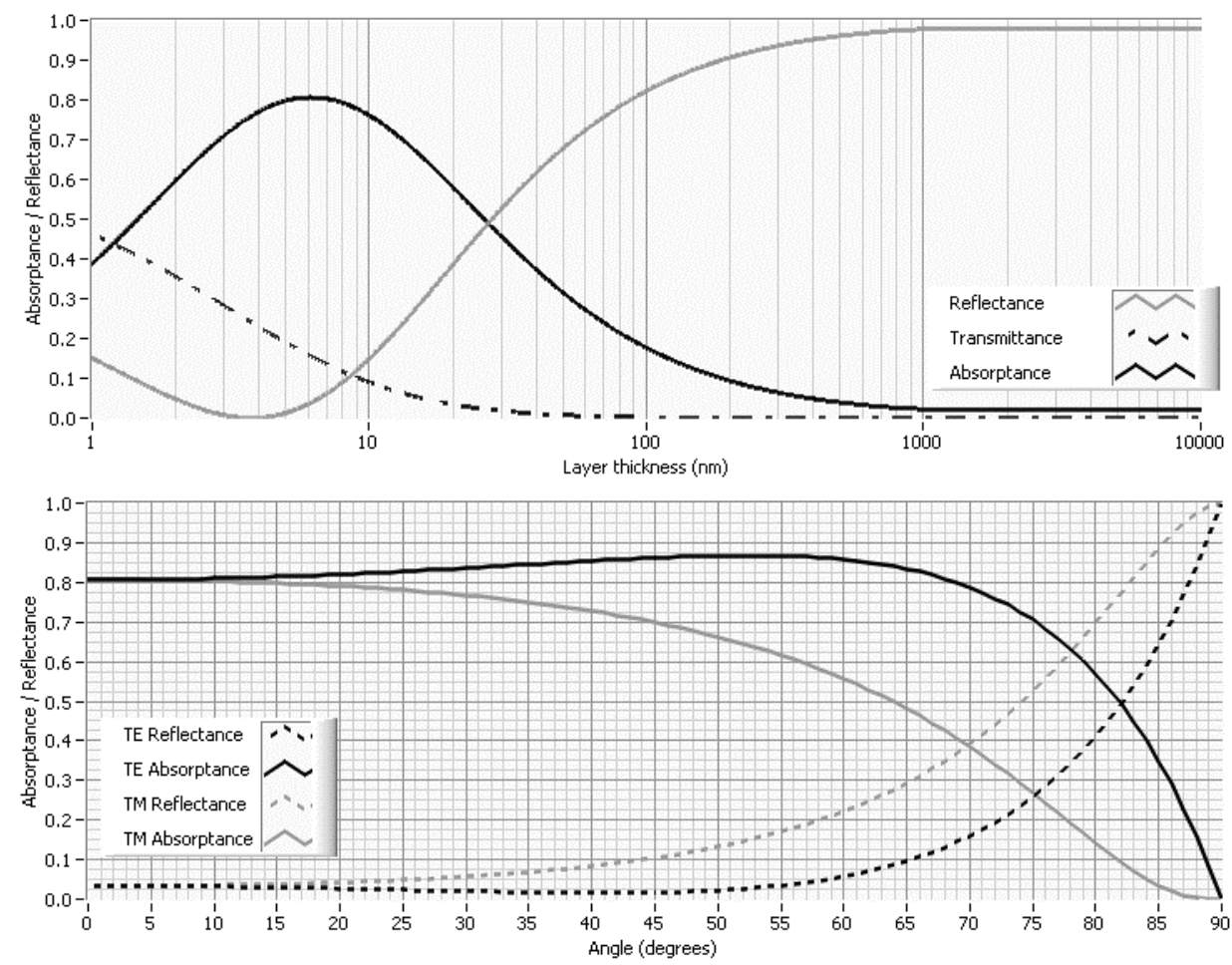

FIGURE 9. (Top) HfC susceptor performance at $140 \mathrm{GHz}, 45 \mu \Omega . \mathrm{cm}$.

(Bottom) $6 \mathrm{~nm}$ HfC susceptor off-normal response at $140 \mathrm{GHz}, 45 \mu \Omega . \mathrm{cm}$.

It is unclear how long an $\mathrm{HfC}$ layer only $6 \mathrm{~nm}$ thin can survive in a high temperature hydrogen channel flow that may carry surface-eroding microparticulates. It could also be difficult to realize the full temperature capability of an HfC susceptor because it would 
have to bond with a material of lower melting point, such as $\mathrm{BN}$, to contain the high pressure propellant flow. The absorption fraction of a thin layer susceptor varies with the product of conductivity and thickness, rather than either quantity individually, and this means that an HfC refractory foam of 100 times lower conductivity could be 100 times thicker. At the present time, resistivity data for refractory foams is not readily available. This being the case, the most practical susceptor approach at present appears to be to accept lower temperature operation and embed the susceptor within the BN layer, thereby protecting it from the hydrogen flow.

\section{CONCLUSIONS}

These examples illustrate the many possible ways there are to construct a microwave thermal thruster, and by microfabrication standards these are simplistic. An ultra-high performance solution approaching the $\mathrm{HfC}$ temperature limit appears a longer term proposition requiring micro-structured materials or micro-structured thruster channels, perhaps even operating with partial liquid phases. Happily, such advances are unnecessary with the modest performance needed for the microsatellite launcher of [1], since these needs can be met with the simplistic approaches outlined here.

Optical properties of the materials presented will differ at high temperature in some cases. This is an important area of further study, and yet another avenue of possibility for a practical thruster design, as is the case for the doped boron nitride thruster. We have shown that different materials and arrangements should efficiently absorb $140 \mathrm{GHz}$ microwaves, doing so even at the off-incidence conditions needed by the ascent trajectory. A successful thruster design must bring together a strong and mass-efficient structure that for a short time resists oxidation on the outside and reduction on the inside, avoiding thermal expansion issues with careful design. There is no fundamental reason why this cannot be done, and there are many practical ways that it can be done. With the precedent of nuclear thermal propulsion offering many examples of success in this precise context, there is every reason to expect that the microwave thermal thruster can become a truly revolutionary form of propulsion.

\section{ACKNOWLEDGMENTS}

We would like to thank Prof. William Bridges, Prof. David Rutledge, Prof. Hans Hornung, Mr. Tobias Kippenburg, Mr. Sean Spillane, Dr. Mark Barton, and Dr. Jordin Kare for helpful conversations. We would also like to thank the Caltech President's Fund for funding this work under grant PF-495 / NASA contract NAS7-1407.

\section{REFERENCES}

1. Parkin, K.L.G., and Culick, F.E.C, "Feasibility and Performance of the Microwave Thermal Rocket Launcher" in Proc. Second International Symposium on Beamed Energy Propulsion-2003, New York: American Institute of Physics. 
2. The National Institute of Standards and Technology, NIST Chemistry WebBook, (http://webbook.nist.gov/).

3. Leavenspiel, O., Engineering Flow and Heat Exchange, New York: Plenum Press, 1998, pp. 174-175.

4. White, F.M., Viscous Fluid Flow, $2^{\text {nd }}$. Ed., McGraw Hill, 1991, pp. 28-29.

5. Pierson, H.O., Handbook of Refractory Carbides and Nitrides, Westwood, New Jersey: Noyes Publications, 1996.

6. Born, M., and Wolf, E., Principles of Optics, Cambridge: Cambridge University Press, 2002, pp. 54-74, pp. 735-758.

7. Ioffe Physico-Technical Institute, Electronic Archive of New Semiconductor Materials, Characterstics, and Properties. St. Petersburg, (http://www.ioffe.ru/SVA/NSM/Semicond/BN/).

8. Buffler, C.R., "A Simple Approach to the Calculation of Microwave Absorption, Transmission, and Reflection of Microwaves from a Susceptor Film", Microwave World, 12 (3), 5-7 (1991).

9. "Nuclear Rockets" in Propulsion Techniques, edited by P.J. Turchi, Reston, Virginia: AIAA Press, 1998, pp. 181-273. 